Gut, 1979, 20, 28-32

\title{
Reversal of ammonia coma in rats by L-dopa: a peripheral effect
}

\author{
L. ZIEVE 1 , W. M. DOIZAKI, AND R. F. DERR \\ From the Department of Medicine, Hennepin County Medical Center and Minneapolis Veterans Hospital, \\ University of Minnesota, Minneapolis, Minnesota, USA
}

\begin{abstract}
SUMMARY Ammonia coma was produced in rats within 10 to 15 minutes of an intraperitoneal injection of $1.7 \mathrm{mmol} \mathrm{NH} \mathrm{N}_{4} \mathrm{Cl}$. This coma was prevented with $1.68 \mathrm{mmol} \mathrm{L}$-dopa given by gastric intubation 15 minutes before the ammonium salt injection. The effect of L-dopa was correlated with a decrease in blood and brain ammonia, an increase in brain dopamine, and an increase in renal excretion of ammonia and urea. Intraventricular infusion of dopamine sufficient to raise the brain dopamine to the same extent did not prevent the ammonia coma nor affect the blood and brain ammonia concentrations. Bilateral nephrectomy eliminated the beneficial effect of L-dopa on blood and brain ammonia and the ammonia coma was not prevented. Thus, the reduction in blood and brain ammonia, and the prevention of ammonia coma after L-dopa, can be accounted for by the peripheral effect of dopamine on renal function rather than its central action. These results provide a reasonable explanation for the beneficial effects observed in some encephalopathic patients receiving L-dopa.
\end{abstract}

The arousal effect of L-dopa in hepatic coma has been observed repeatedly since the original observations (Parkes et al., 1970). The arousal response is observed in approximately one-half of patients treated and is temporary in all but a few (Fischer et al., 1976). The beneficial effect of L-dopa has generally been presumed to be a central effect of its derivative, dopamine, and has been cited as evidence supporting the false neurotransmitter hypothesis of the aetiology of hepatic coma (Fischer and Baldessarini, 1971). We studied the effect of L-dopa in experimental ammonia coma in rats, thinking that there might be an association between the arousal effect of L-dopa and the brain ammonia concentration. We found, indeed, that L-dopa in sufficient dosage prevented ammonia coma, and that the presence or absence of coma was related to the brain ammonia but not the brain dopamine concentration. We also observed that the reduction in brain and blood ammonia after L-dopa was associated with an increase in renal excretion of ammonia and urea, and that nephrectomy eliminated the effects of L-dopa on coma and on the blood and brain ammonia concentrations.

${ }^{1}$ Address for reprint requests: Dr Leslie Zieve, Hennepin County Medical Center, 701 Park Ave. S., Minneapolis, MN 55415, USA.

Received for publication 19 June 1978

\section{Methods}

\section{EXPERIMENTAL PROCEDURE}

Healthy male Sprague-Dawley rats weighing 275$350 \mathrm{~g}$ were used. One set of non-fasting animals was divided into four groups consisting of five or six rats per group. The animals of the first group received only an intraperitoneal injection of a comaproducing dose of $\mathrm{NH}_{4} \mathrm{Cl}, 1.7 \mathrm{mmol}$. Coma occurred in all animals within 10 to 15 minutes as judged by their failure to roll over when placed upon their backs and their lack of response to a painful stimulus. Blood was drawn for ammonia determination within two to four minutes after onset of coma (12 to 18 minutes after injection of the $\mathrm{NH}_{4} \mathrm{Cl}$ ). Each animal was exsanguinated, the head decapitated immediately thereafter, and the brain quickly extracted from the skull and frozen in liquid nitrogen, to be saved for later analysis for ammonia, dopamine, and noradrenaline. The whole process of getting and freezing the brain took less than two minutes.

The animals of the second group received L-dopa, $1.68 \mathrm{mmol}$ by intubation 15 minutes before they received $1.7 \mathrm{mmol} \mathrm{NH}_{4} \mathrm{Cl}$ intraperitoneally. Coma did not occur in any of these rats, though two became lethargic. Blood was drawn for ammonia determination 17 to 20 minutes after the injection of $\mathrm{NH}_{4} \mathrm{Cl}$. 
The remainder of the procedure was similar to that for the first group.

The rats of the third group received L-dopa, $1.68 \mathrm{mmol}$, by intubation like those of the second group. In addition, they were injected intraperitoneally with $150 \mathrm{mg}$ benserazide, a dopa decarboxylase inhibitor, 15 minutes before they received the intraperitoneal injection of $1.7 \mathrm{mmol}$ $\mathrm{NH}_{4} \mathrm{Cl}$. Three of these rats became comatose, two lethargic, and only one remained alert. Blood was drawn for ammonia determination 16 to 17 minutes after the injection of $\mathrm{NH}_{4} \mathrm{Cl}$. The remainder of the procedure was similar to that for the first group.

The rats of the fourth group received $1.4 \mu \mathrm{g}$ dopamine through a cannula placed in the lateral ventricle of the cerebrum as described previously (Zieve and Olsen, 1977). The infusion of dopamine occurred over a period of 30 minutes before the intraperitoneal injection of $1.7 \mathrm{mmol} \mathrm{NH}_{4} \mathrm{Cl}$. Coma occurred in all animals within seven to 12 minutes, and blood was drawn for ammonia determination three to four minutes later. The exsanguination and taking of the brain was similar to that for the first group.

The urinary excretion of ammonia and urea was studied in a second set of non-fasting rats of similar size. Two groups were formed and housed individually in metabolism cages. One group (six rats) received $5 \mathrm{ml}$ water and 15 minutes later a coma producing dose of $\mathrm{NH}_{4} \mathrm{Cl}(1.7 \mathrm{mmol})$ intraperitoneally. The rats were killed 20 minutes after the ammonia injection. The bladder was flushed three times with water and the bladder washings combined with the metabolism cage washings and analysed for ammonia and urea. A second group of seven rats was treated exactly the same way, except that each received $1.68 \mathrm{mmol} \mathrm{L}$-dopa by intubation 15 minutes before the injection of $\mathrm{NH}_{4} \mathrm{Cl}$.

A third set of 34 rats that had fasted for 24 hours was subdivided into four groups. The first two groups were treated the same as the corresponding groups of the first set of rats and served as controls for the third and fourth groups of rats, which were nephrectomised two hours before receiving $\mathrm{NH}_{4} \mathrm{Cl}$ or L-dopa and $\mathrm{NH}_{4} \mathrm{Cl}$ in identical fashion to the first two groups. Coma occurred faster in the nephrectomised rats, about six minutes after the injection of $\mathrm{NH}_{4} \mathrm{Cl}$. Blood was drawn for ammonia determinations within two to three minutes of onset of coma and the brain taken as before.

\section{ANALYTICAL METHODS}

Blood and urine ammonia were determined promptly after collection by the procedure of Reinhold and Chung (1961). Brain ammonia was measured similarly after homogenisation of a frozen piece. Brain dopamine and noradrenaline were measured by the procedure of Refshauge et al. (1974) as previously described by Zieve and Olsen (1977). Urine and blood urea were measured by the procedure of Mather and Roland (1969).

\section{Results}

Figure 1 gives results of blood and brain ammonia

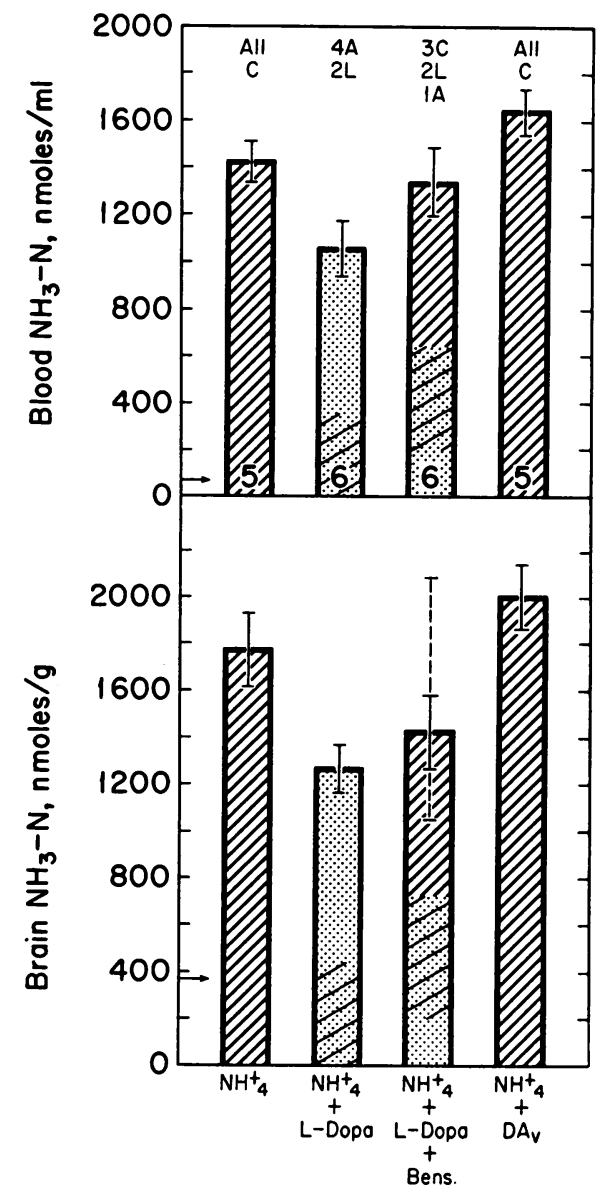

Fig. 1 Effect of various treatment combinations on the blood and brain ammonia concentrations and on the production of coma. The number of rats in each of the four groups is shown at the base of the upper set of bars. The bars show the means $\pm S E M$. The dashed line extensions of the vertical line on the third bar of the lower set represent the range of values in this case. $C=$ coma,$A=$ alert, $L=$ lethargic, Bens $=$ benserazide, $D A_{\mathrm{v}}=$ intraventricular dopamine. Diagonal lines in bars indicate coma; dots indicate alertness; dots overlaid with widely spaced diagonal lines indicate lethargy. Horizontal arrows along ordinate indicate average normal values of the variables measured. 
nitrogen measurements (henceforth referred to simply as blood or brain ammonia). As shown in the upper section of the figure, the average blood ammonia concentration within a few minutes of the onset of coma was $1424 \mathrm{nmol} / \mathrm{ml}$, equivalent to approximately $2400 \mu \mathrm{g} / \mathrm{dl}$. For reference, the average blood ammonia in six normal uninjected rats of equivalent weight was $71 \mathrm{nmol} / \mathrm{ml}$ as shown by the arrow on the ordinate. The blood ammonia was reduced significantly $(t=2.5, \mathrm{P}<0.05)$ by approximately $25 \%$ when $1.68 \mathrm{mmol}$ L-dopa, a large dose, was given by gastric intubation 15 minutes before the intraperitoneal injection of $\mathrm{NH}_{4} \mathrm{Cl}$, and coma was prevented as shown by the second bar. The dopa decarboxylase inhibitor benserazide prevented this beneficial effect of L-dopa to a significant degree as shown by the third bar. A large dose of benserazide, $500 \mathrm{mg} / \mathrm{kg}$, was required to produce this effect. Only one of six rats remained alert and three became comatose. Direct instillation of dopamine into the cerebral ventricle, unlike oral L-dopa, did not prevent coma and had little effect on the blood ammonia.

The effects of these manipulations on brain ammonia were similar. The reduction in brain ammonia by L-dopa was approximately $30 \%$ $(t=2 \cdot 8, \mathrm{P}<0.05)$, and coma was prevented though a dose of $\mathrm{NH}_{4} \mathrm{Cl}$ that normally produced coma was given. Benserazide reversed the effect of L-dopa in three of six rats, though the average brain ammonia for the group did not return to the level of the first group. In this instance, the range of values observed is indicated by the dashed vertical line. As with blood ammonia, instillation of dopamine directly into the cerebral ventricle had no effect on the brain ammonia and did not prevent ammonia coma.

As can be seen in Fig. 2, brain dopamine and noradrenaline did not change significantly from the normal (shown by arrows) after the injection of a coma-producing dose of $\mathrm{NH}_{4} \mathrm{Cl}$. When the oral dose of L-dopa was added brain dopamine increased by $40 \%(t=4.2, \mathrm{P}<0.01)$, while the brain noradrenaline remained unchanged. Benserazide prevented the rise in brain dopamine after L-dopa. The intraventricular instillation of $1.4 \mu \mathrm{g}$ dopamine also caused a rise in brain dopamine of approximately $40 \%$ but, as seen previously, coma was not prevented.

In Fig. 3 the alterations in brain ammonia and brain dopamine are contrasted in relation to the presence and absence of coma after the injection of $1.7 \mathrm{mmol} \mathrm{NH}_{4} \mathrm{Cl}$. Only the brain ammonia rose and fell consistently with the presence and absence of coma. Brain dopamine increased significantly after intraventricular instillation of dopamine, as it did

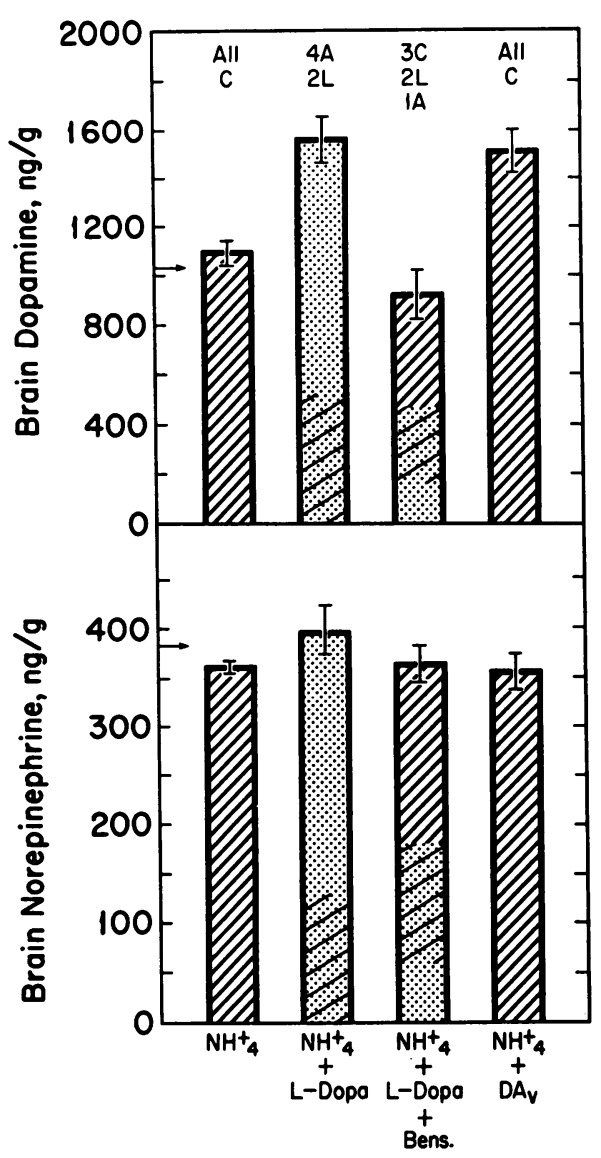

Fig. 2 Effect of various treatment combinations on the brain dopamine and noradrenaline concentrations and on the production of coma. Where applicable, the remainder of the legend is the same as for Fig. 1.

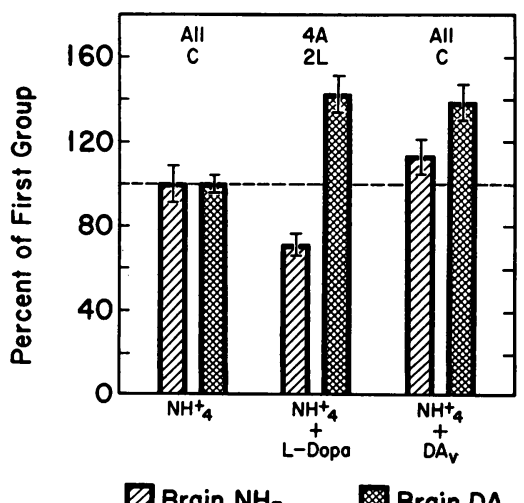

Fig. 3 Relative changes in brain ammonia and brain dopamine in response to $\mathrm{NH}^{+}$, plus oral L-dopa or intraventricular dopamine. Bars show means $\pm S E M$. 
after oral L-dopa, but coma was not prevented and the brain ammonia did not fall. This lack of effect of intraventricular dopamine on the brain ammonia in contrast to that of oral L-dopa, suggested to us that the beneficial effect of the L-dopa on ammonia coma might be due to its effect on ammonium ion availability. We therefore studied the effect of L-dopa on the renal excretion of ammonia and urea after a loading dose $(1.7 \mathrm{mmol})$ of $\mathrm{NH}_{4} \mathrm{Cl}$.

In Fig. 4 are shown the effects of L-dopa on

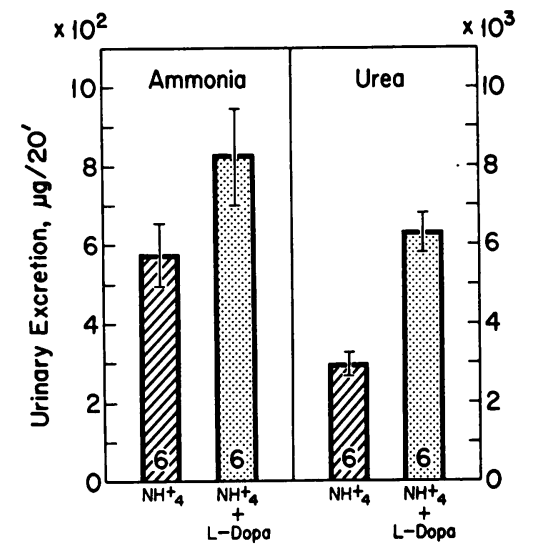

Fig. 4 Effect of L-dopa on urinary excretion of ammonia and urea after the coma-producing dose of $\mathrm{NH}_{4} \mathrm{Cl}$. Bars show means \pm SEM. Number of animals shown at base of bars.

urinary ammonia and urea after the coma-producing dose of $\mathrm{NH}_{4} \mathrm{Cl}$. The mean ammonia excretion increased by $44 \%$ and urea excretion by $114 \%$. The variability of ammonia excretion was great, preventing statistical significance $(t=1 \cdot 7, \mathrm{P}>0 \cdot 1)$ for this increase, however, the median increase was $54 \%$. The increase in urea excretion was highly significant $(t=5.85, \mathrm{P}<0.001)$.

If the results of Fig. 4 indicate a renal basis for the coma-preventing effect of L-dopa, nephrectomised rats given the same doses of $\mathrm{NH}_{4} \mathrm{Cl}$ and L-dopa should remain in coma. That this is the case is shown in Fig. 5 which gives the blood and brain ammonia concentration in a group of nephrectomised rats and another control group run at the same time. The controls show the same reduction $(27 \%)$ in blood $(t=4.16, \mathrm{P}<0.001)$ and brain $(t=3.04, \mathrm{P}<0.02)$ ammonia concentrations on pretreatment with L-dopa as observed in the first set of rats. The nephrectomised rats show no effect of L-dopa on the occurrence of coma or on the concentrations of blood and brain ammonia. The blood ammonia values in the nephrectomised rats were about $35 \%$ higher than in the controls, as

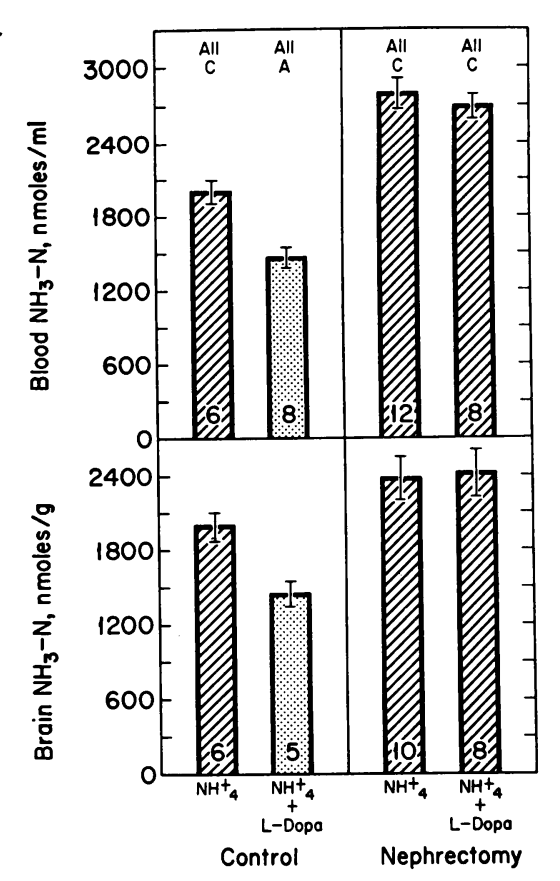

Fig. 5 Effect of $\mathrm{L}$-dopa on the production of coma and on blood and brain ammonia concentrations in nephrectomised rats after the coma-producing dose of $\mathrm{NH}_{4} \mathrm{Cl}$. Where applicable, the remainder of the legend is the same as for Fig. 1.

might be expected. The blood urea nitrogen in the controls after injection of the coma-producing dose of $\mathrm{NH}_{4} \mathrm{Cl}$ was $41 \pm 1.5 \mathrm{mg} / \mathrm{dl}$, and in the rats two hours after nephrectomy $65 \pm 3.0 \mathrm{mg} / \mathrm{dl}$. L-dopa had no significant effect on these values.

\section{Discussion}

The data of this report demonstrate that ammonia coma can be reversed by L-dopa and that this effect is probably related to a renal effect of dopamine rather than the build-up of dopamine in the brain. This study has implications for the observations of the L-dopa effect in hepatic coma. It has been assumed that the arousal effect of L-dopa in hepatic coma is a consequence of an increase in brain dopamine that presumably occurs (Parkes et al., 1970, Fischer et al., 1976). This thought has been used in support of the false neurotransmitter hypothesis of pathogenesis of hepatic coma (Fischer and Baldessarini, 1971). The increase in brain dopamine after ingestion of L-dopa was probably real and the correlation of this increase with improvement in the encephalopathy was likely, as we demonstrated in our rats with ammonia-induced 
coma. However, the simultaneous occurrence of other effects from the increase in systemic dopamine after L-dopa ingestion was ignored.

Two of the striking effects of dopamine are on renal function and on the circulation. Dopamine increases renal blood flow and glomerular filtration. It also increases cardiac output and decreases peripheral resistance. In 1964, McDonald et al. studied the cardiovascular and renal effects of an intravenous infusion of dopamine at a rate of 4-5 $\mu \mathrm{g} / \mathrm{kg} / \mathrm{min}$. Renal blood flow increased by an average of $57 \%$ in nine normal people and by $48 \%$ in seven with congestive heart failure. Corresponding increases in sodium excretion were three- and fourfold. The cardiac output in the normal subjects increased by $48 \%$ and the peripheral resistance decreased by $33 \%$.

In another study of the effect of a single 1-2 g dose of L-dopa in seven patients with Parkinson's disease, Goldberg and his colleagues (Finlay et al., 1971) found the average renal blood flow increased by $20 \%$, the excretion of potassium increased by $40 \%$, and the excretion of sodium increased by $150 \%$. There is thus every reason to anticipate that another renal effect of L-dopa or dopamine would be increased excretion of ammonia and urea among other substances. Thus our rats given an excess of $\mathrm{NH}^{+}{ }_{4}$ responded to the L-dopa they received with increased renal excretion of ammonia and urea, sufficient to reduce the blood and brain ammonia by $25-30 \%$. This modest reduction in ammonia concentration was apparently enough to bring the animals below the coma level for this substance. When the kidneys were removed the beneficial effect of L-dopa on the blood and brain ammonia was eliminated and the rats were not protected from the coma-producing dose of $\mathrm{NH}_{4} \mathrm{Cl}$. We suggest that this renal effect may be the basis for the beneficial results seen with L-dopa in hepatic encephalopathy.

We are indebted to Carolyn Lyftogt, Kay Draves, and Sandra Lindblad for excellent technical assistance. We also thank Dr W. E. Scott of HoffmanLaRoche Inc. for a generous gift of benserazide.

\section{References}

Finlay, G. D., Whitsett, T. L., Cucinell, E. A., and Goldberg, L. I. (1971). Augmentation of sodium and potassium excretion, glomerular filtration rate and renal plasma flow by levodopa. New England Journal of Medicine, 284, 865-870.

Fischer, J. E., and Baldessarini, R. J. (1971). False neurotransmitters and hepatic failure. Lancet, 2, 75-80.

Fischer, J. E., Funovics, J. M., Falcao, H. A., and Wesdorp, R. I. C. (1976). L-Dopa in hepatic coma. Annals of Surgery, 183, 386-391.

McDonald, R. H., Goldberg, L. I., McNay, J. L., and Tuttle, E. P., Jr. (1964). Effects of dopamine in man: augmentation of sodium excretion, glomerular filtration rate, and renal plasma flow. Journal of Clinical Investigation, 43, 1116-1124.

Mather, A., and Roland, D. (1969). The automated thiosemicarbazide-diacetyl monoxime method for plasma urea. Clinical Chemistry, 15, 393-396.

Parkes, J. D., Sharpstone, P., and Williams, R. (1970). Levodopa in hepatic coma. Lancet, 2, 1341-1343.

Refshauge, C., Kissinger, P. T., Dreiling, R., Bland, L., Freeman, R., and Adams, R. N. (1974). New high performance liquid chromatographic analysis of brain catecholamines. Life Sciences, 14, 311-322.

Reinhold, J. G., and Chung, C. C. (1961). Formation of artifactual ammonia in blood by action of alkali. Its significance for the measurement of blood ammonia. Clinical Chemistry, 7, 54-69.

Zieve, L., and Olsen, R. L. (1977). Can hepatic coma be caused by a reduction of brain noradrenaline or dopamine? Gut, 18, 688-691. 